arch are gradually strengthened until such time as the mechanical support can be dispensed with and the arch maintained by muscles and ligaments that have been rested and restored to function.

\section{Treatment of Backache}

In the treatment of backache the most essential factor is the provision of adequate support and rest. This problem is not as simple as it appears at first sight. The support must be adjusted to the exact degree demanded by the patient to afford relief and comfort. In other words, it must relax the strained spinal ligaments and the musculature. A support which is too strong or too weak will fail in its purpose. Rest in bed without an arch support is of little value, and, in fact, is often harmful, as the vast majority of beds sag, the patient lying in a saucershaped hollow, with shoulders and feet well above the level of the lumbar arch, which becomes dorsiflexed. An ordinary cushion is of little use, as it cannot be suitably adjusted. It is obvious that the degree of support will vary according to the patient's body weight, the type of arch, and the attitude of the body-that is, the angle it makes with the horizontal at the point where the sacrum impinges on the bed.

To fulfil these conditions a simple apparatus has been devised, which has given most gratifying results in practice. Briefly the device consists of a rubber bag large enough to cover the lumbar arch, to which is connected a piece of rubber tubing sufficiently long to be brought round to the front of the patient. To the free end of the tubing is attached a valve and bulb, similar to that used on a sphygmomanometer. The rubber cushion is easily inflated to the required degree, the valve being used as a control. By its aid the back can be maintained in a constant state of relaxation and freedom from' strain; only in this way can aching be effectively remedied.

Generally speaking, faulty posture in bed produces not only much discomfort, backache, disturbed sleep, and avoidable suffering, but other more serious effects. The typical patient propped up in the Fowler or sitting position has his back bent and lumbar arch flattened, with the result that the diaphragm is cramped and its function impaired. Consequently the patient ceases to breathe deeply, the lower lobes of the lungs are not ventilated satisfactorily, and post-operative pulmonary complications are very probable sequels. Finally, in all ailments, whether of the thoracic, abdominal, or pelvic viscera, faulty posture by crowding the organs, producing congestion, and interfering with function, must hamper successful treatment.

\section{Summary}

1. Faulty posture is the main cause of backache.

2. It is suggested that it is also a predisposing cause of much disease of the female pelvic organs.

3. An adjustable pneumatic support, devised for the relief of backache, is described.

I am indebted to Dr. James Young, Edinburgh, who has kindly given me permission to state that he has used the cushion device in the Royal Infirmary and in private practice for the last six months and has found it of great value. I am also much indebted to Mr. Leonard Phillips for the facilities he has given me to use the cushion for patients under his care at the Hospital for Women, Soho Square.

A detailed report on the results of this method of treatment will be published. The cushion has been made for me by Messrs. P. B. Cow and Co., Ltd., 46, Cheapside, London, E.C.2.

\section{REFERENCES}

I Adams: Amer. Journ. Obstet. and Gynecol., 1927, xiv, 742

${ }^{2}$ Goldthwaite: Shattuck Lecture, 1915, Boston Med. and Surg. Journ., clxxii, 881

${ }^{3}$ Ogilvie: Recent Advances of Surgery, 1929, 206.

4 Comyns Berkeley: Practitioner, 1911, lxxxvii, 477.

\section{SEPTICAEMIA AND ENCEPHALITIS IN RELATION TO VACCINATION}

BY

\author{
ROBERT PRIEST, M.B., M.R.C.P. \\ MAJOR, R.A.M.C.
}

In their article on septicaemia and encephalitis in relation to vaccination, published in the British Medical Journal of June 21st, 1930, Drs. Temple Grey and Whittaker draw the all-important conclusion that no condition can be fairly described as encephalitis pure and simple unless septicaemia has been excluded as a possible cause by appropriate bacteriological examinations; and, further, that all cases of severe illness occurring in the three weeks after vaccination should be under hospital treatment in order that the special examinations may be performed, and if death occurs the necropsy should include bacteriological and histological investigation of the other tissues as well as those of the central nervous system. These conclusions, and the need for eliminating all other morbid conditions before ascribing any clinical cerebral or encephalitic signs to primary vaccination in an adult, prompt me to record a case, very similar to the first one of those reported by these authors, which was under my care.

\section{Clinical History of Case}

A recruit, aged 18, was admitted to the Queen Alexandra Military Hospital on May 27th, 1930, with a history of being ill for four days with headache and dizziness, and some frequency of micturition and diplopia. There was also malaise and loss of appetite, but no nausea or vomiting. He had harl influenza in 1929; he had never been abroad. $\mathrm{He}$ was vaccinated for the first time in his life on May 7th, 1930, with Government lymph, in two places on the left arm just below the deltoid. On admission his temperature was $104.6^{\circ}$, pulse 124 . The vaccination sites showed healthy scabs, with no surrounding inflammation. There were some septic sores on the skin over both insteps, and another septic area, partially covered with an unhealthy scab and surrounded by an area of cellulitis, in the region of the left external malleolus. The toes of the left foot also appeared to be inflamed. The lungs showed no evidence of active disease, but there was some deficiency of air entry and some impairment of note at the left base. The heart did not appear enlarged; there was no thrill, but the first sound at the apex was roughened. Liver edge not felt; spleen not palpable. The patient's mind was clear. The diplopia of which. he had complained at the oriset was no longer present; there was no squint, and the pupils reacted normally. Abdominal reflexes were absent, knee-jerks sluggish and difficult to obtain, right ankle-jerk absent, left plantar response "flexor," right doubtful. Sphinters controlled. There was slight but obvious ptosis of the eyelids, more marked on the right side.

On May 28th the temperature was $104.4^{\circ}$, pulse 120. Lumbar puncture showed the cerebro-spinal fluid to be under no increase of pressure ; the fluid was clear and found to be sterile on culture. Lymphocytes present 6 per c.mm.; no increase of globulin or sugar. The Wassermann reaction proved negative. Blood culture produced a growth of Staphylococcus albus. Total leucocytes 14,000 ; polymorphonuclears 84 per cent., small lymphocytes 8 per cent., large lymphocytes 4 per cent., hyalines 3 per cent., eosinophils 1 per cent. Red blood cells 5,600,000; haemoglobin 80 per cent.

On May 29th the temperature was $104^{\circ}$, pulse 132 . The right ptosis was more distinct, and there were now signs of meningeal involvement as shown by neck rigidity, irritability, and hypersensitiveness. There were epistaxis and twitching of the right eyelids, the limbs were much more rigid, plantar reflexes "flexor," abdominal, cremasteric, and epigastric reflexes absent. Arm-jerks were not obtained, except a feeble response in left triceps; knee-jerks absent, right ankle-jerk absent, left brisk. No diplopia, pupils normal. Sphincters controlled. Lumbar puncture proved the cerebrospinal fluid to be clear and under no pressure. 
On May 30th, after a very restless night, the patient was comatose, and showed a very definite paresis of the right face, arm, and leg ; the right plantar reflex " extensor," right abdominal reflex absent, left present; some areas of haemorrhage, with some induration, noted over the toes of both feet, under the skin of the left thigh, and a few small pyaemic-looking areas on the back. He was seen by Colonel W. P. MacArthur, who agreed that the condition was one of septicaemia, and, owing to the presence of the systolic bruit, and to the fact that the spleen was now just palpable, formed the opinion that the clinical picture was one of acute infective endocarditis. The patient gradually became weaker, and just before he succumbed on the early morning of May 31 st his temperature had risen to $106^{\circ}$.

\section{Post-mortem Findings}

At necropsy the two vaccination sites appeared clean and healthy. There were haemorrhages present on the toes of the feet and on the left thigh. The lungs appeared normal. The fluid in the pericardial cavity was blood-stained, numerous vegetations were seen on the mitral valve and on the wall of the left ventricle. No vegetations were seen on the right valves or heart wall. The liver weighed $3 \mathrm{lb} .1 \mathrm{oz}$; no macroscopic abnormality noticed. The spleen was enlarged and soft, and weighed $18 \mathrm{oz}$. In the right kidney there were multiple infarcts; one appeared to be very recent and the others were organized ; the left kidney appeared to be normal, and no lesions were seen macroscopically. Microscopical examination of the brain showed thrombosis in the blood vessels, softening of brain substance, and round-cell infiltration. Many of the smaller vessels were congested, and a great excess of leucocytes, mostly polymorphonuclears, was seen within the lumen. On examination of the septic vegetations from the heart valves large masses of Gtam-positive micrococci were seen emmeshed within the film covering of the valves.

This case, then, presenting as it did diplopia, headaches, ptosis, the subsequent meningeal signs, rigidity and coma, might have led to a diagnosis of post-vaccinal encephalitis ; and, should the question of compensation have arisen, it would have been very difficult to dissociate the two conditions without the careful daily observation while in hospital and without the assistance of the post-mortem findings.

\section{Memoranda}

\section{MEDICAL, SURGICAL, OBSTETRICAL}

\section{THE PREVENTION OF PUERPERAL PYREXIA}

The following statistics showing the effect of Parke Davis's antistreptococcic puerperal serum as a preventive of puerperal sepsis may prove of interest to those who are engaged in obstetric practice. The apparent beneficial results of this serum can be readily understood by studying the annual returns at Bellshill Hospital before and after its routine administration in complicated cases, and also in normal cases with laceration of the perineum. Our experience has been that the best results are obtained by the administration of the serum in large doses; 50 to $70 \mathrm{c.cm}$. should be given during labour, or a few days prior to its onset if trouble is anticipated. Procrastination deprives the patient of an opportunity to escape the sequels of infection. Apart from the occurrence of a rash, no inconvenience is experienced. The rash does not appear in some instances, and when it does it varies in frequency and intensity with different batches of serum. We are inclined to regard the occurrence of a rash as a favourable omen. The only other disturbance worthy of note is the not infrequent onset of uterine haemorrhage (15 per cent.) about the eighth to the tenth day, but the loss is not sufficient to create anxiety.
$\Lambda$ short explanatory note about the figures is necessary. In 1925 and 1926 serum was not used, but during 1927 and 1928 we began administering this serum, which Parke, Davis and Co. placed at our disposal free of charge for clinical experiment. At this time the output of serum was small, so that only a limited number of cases could be treated. Nevertheless the results were so encouraging that we determined to employ it extensively. During 1929 and 1930 it was given in all complicated cases, and in normal cases where the perineum was torn ; the results have been gratifying. Since Mellanby's communication ${ }^{1}$ appeared on the value of a dict rich in vitamin $A$ as a preventive of puerperal sepsis in rats, we have advised our patients to partake freely of a diet consisting of fresh vegetables, carrots, cheese, and liver. As this paper appeared only recently, we have not yet obtained a sufficiently large number of cases to estimate if the incidence of puerperal pyrexia in our cases has diminished.

\begin{tabular}{|c|c|c|c|c|}
\hline \multirow[t]{2}{*}{ Date } & \multirow{2}{*}{\multicolumn{2}{|c|}{ Number of Cases }} & \multicolumn{2}{|c|}{$\begin{array}{c}\text { Puerperal Pyrexia } \\
\text { According to B.M.A. } \\
\text { Standard }\end{array}$} \\
\hline & & & Number & Percentage \\
\hline 1925 & 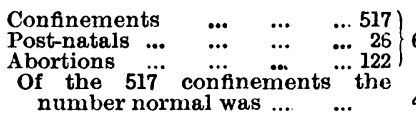 & & 50 & 7.5 \\
\hline 1926 & 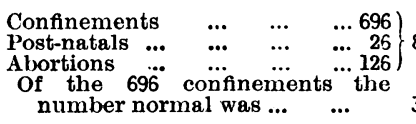 & $\begin{array}{l}848 \\
380\end{array}$ & 55 & 6.5 \\
\hline 1927 & 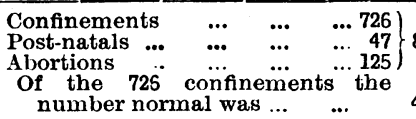 & $\begin{array}{l}898 \\
432\end{array}$ & not & 5.0 \\
\hline 1928 & 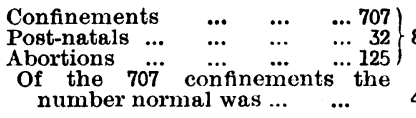 & $\begin{array}{l}864 \\
432\end{array}$ & 10 & 4.7 \\
\hline 1929 & 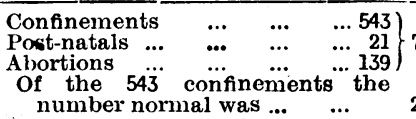 & $\begin{array}{l}703 \\
279\end{array}$ & Nil & 2.8 \\
\hline 1930 & 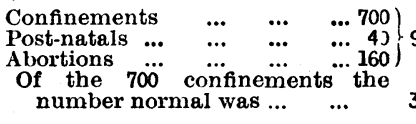 & $\begin{array}{l}9 c 0 \\
308\end{array}$ & 19 & 2.1 \\
\hline
\end{tabular}

In 1925 and 1926 no serum was used, and in 1927 and 1928 a limited supply only. In 1927 and 1930 serum was used in all complicated cases, and in

Radiostoleum is also mentioned by Mellanby as a suitable preparation where vitamin $A$ is required, so we have been using either radiostoleum or adexolin, which contains vitamins $A$ and $D$.

It seems to us that in obstetrical cases fortifications should be erected early to prevent puerperal infection, and it may be that this aid can be obtained to a large extent by diet and by the administration of serum. The disadvantage is great if the invader is permitted to demonstrate within the citadel.

It is unfortunate that treatment by serum proves expensive, but it should not be forgotten that the victims of puerperal sepsis often have a long and costly illness. The administration of serum during labour curtails convalescence in cases where pyrexia develops.

$$
\begin{gathered}
\text { Samuel J. Cameron, M.B., } \\
\text { F.R.F.P.S., } \\
\text { Consulting Surgeon, } \\
\text { Henry Thomson, M.D., } \\
\text { Physician in Charge, } \\
\text { County of Lanark Maternity Hospital, } \\
\text { Bellshill. }
\end{gathered}
$$

1 Green, H. N., and Mellanby, E.: Brilish Medical Journal, 1928, ii, 691. 